\title{
Computer-based Test Software System: A Review and New Features
}

\author{
Bajeh Amos Orenyi \\ Department of Computer Science, Faculty of \\ Communication \& Information Sciences, University \\ of Ilorin, Nigeria
}

\author{
Mustapha Mutairu Omotosho \\ Department of Computer Science, Faculty of \\ Communication \& Information Sciences, University \\ of Ilorin, Nigeria
}

\begin{abstract}
Computer Based Test System also referred to as eexaminations System, is a software that can be used to conduct examinations through the internet or in an intranet for a remote or in-house candidates. This paper identify the need for improving the current CBT software systems employed by tertiary institutions. The proposed features for improving the reviewed systems includes state persistency (in order to prevent data loss in case of any interruption or disruptions that may occur during examinations) and Question Categorization (in order to fairly evaluate candidates by posing questions with overall equal strength to each and every candidate taking an examination).

This paper detailed the requirements, design and implementation of the proposed for the improvement of the CBT systems. The implementation of the system was done by the use of C\# programming language, SQL Serever 2005 express edition, Visual studio 2008 express edition as the IDE. The acceptability of the proposed system was evaluated by conducting a survey to sample opinions of users on the improvements in the proposed CBT system.
\end{abstract}

\section{General Terms}

Software Systems, Algorithm, Enterprise Application Development.

\section{Keywords}

Computer Based Test (CBT), Question Categorization, State Persistency, e-examination, 3-tier architecture

\section{INTRODUCTION}

In Educational institutions the evaluation of performance of student is done through Examinations which is one of the most important components of educational systems or institutions. The regularity and integrity in conducting examinations is one of the parameters for measuring the standard and efficiency of an educational institution. The examination system is improved by the computerization of the various examination activities [1].

Tertiary institutions and examination bodies adopt the use of various types of Computer Based Test (CBT) Software
Systems. The benefits of these systems over the traditional/conventional method of examination cannot be over emphasised: it involves the conduct of examinations using computer networks, and questions are set in such a way that they can be formally and easily processed by the computer [2]. This reduces the enormous workload on examiners in manually marking, grading and reviewing examinations. Several studies had been conducted on eexamination system, but none so far (to the best our knowledge at the time of writting this paper) was developed with the features of state persistency, question categorization and the new question type identified and designed in this paper.

\section{REVIEW OF CURRENT SYSTEMS}

The reviewed systems were the Computer Based Test Systems used by some of the top most tertiary institutions in Nigeria, which model the general conventional CBT system.

As Ayo C.K. et al [3] stated, these systems can be considered as a 3-tier architectures systems, comprising the View/Presentation tier, the business-logic tier and the database/Backend tier. The view/presentation tier offers an interface to the user, it is the gateway for users to access the information retrieved from the backend (i.e. the database) on the system. The business-logic tier serves as the middleware that is responsible for processing the user's requests, it can also be regarded as the engine room of the application that is responsible for the overall functionality of the system. The database/bankend tier serves as the repository of all the data required for the operation of the system including but not limited to users data, examination questions, etc.

Below is a high level algorithm (in flowchart form) representing the general architecture of the CBT systems used by the tertiary institutions and reviewed in this work. 


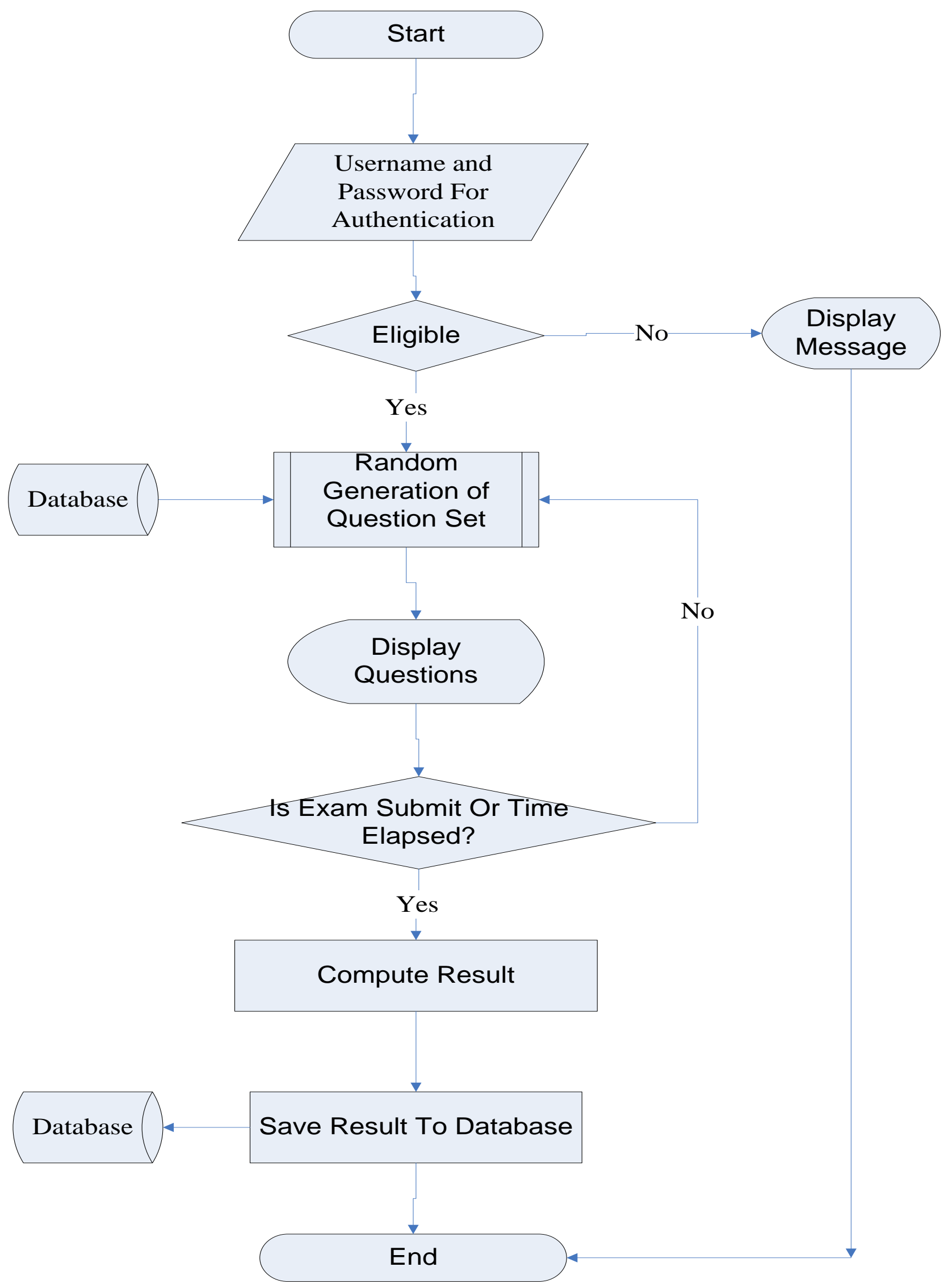

Fig 1: Architecture of the reviewed systems. 
The following are the proposed features, which are not in the reviewed systems, that the CBT systems should have in order to improve them:

1) Questions categorisation : This ensures fairness in the distributuion of questions to candidates and also ensures overall equality in the strength of questions answered by candidates.

2) State persistency: This prevents data loss from any situation that may arise.

3) Addition of another exam type modules : Addition of the response type question greatly increase the flexibility of the system.

A preliminary evaluation of the acceptability of the proposed features for the CBT software systems was conducted to know how strong the users are likely to move towards the development of the new system with its introduced features (i.e. state persistency and question categorization). Analysis of the questionnaires that were distributed are as follows.

Table 1: Result of Survey

\begin{tabular}{|c|c|}
\hline $\begin{array}{c}\text { Total Number Of } \\
\text { Questionnaires Distributed }\end{array}$ & 500 \\
\hline $\begin{array}{c}\text { Number of Recieved } \\
\text { Questionnaires }\end{array}$ & 395 \\
\hline $\begin{array}{c}\text { Number of people that } \\
\text { want the State Persistency }\end{array}$ & 327 \\
\hline $\begin{array}{c}\text { Number of people that } \\
\text { want Question } \\
\text { Categorization }\end{array}$ & 382 \\
\hline $\begin{array}{c}\text { Most Reasons For } \\
\text { Accepting State Persistency }\end{array}$ & $\begin{array}{c}\text { Because of electricity } \\
\text { interuption and hardware } \\
\text { failure }\end{array}$ \\
\hline $\begin{array}{c}\text { Most Reasons for } \\
\text { Categorization }\end{array}$ & $\begin{array}{c}\text { For Fairness Purpose } \\
\text { Mccepting Question }\end{array}$ \\
\hline $\begin{array}{c}\text { Most Reasons for Rejecting } \\
\text { Question Categorizations }\end{array}$ & $\begin{array}{c}\text { Believe that the exam will be } \\
\text { restarted and hence giving } \\
\text { them another set of cheap } \\
\text { questions }\end{array}$ \\
\hline
\end{tabular}

\section{DESIGN OF THE PROPOSED SYSTEM}

The proposed system is the implementation of the new features identified in section 2 and the existing features in the current systems. The new features and their designs are discussed below.

1) Questions categorization: This enable the examiner to set categories for the questions of the exam based on the strength of each question. It is certain that all the questions in an examination do not have the same strength - some questions are harder to solve or requires more time than some other question in the same examination. Questions categorization will place questions with the same strength into the same category. This implies that all questions in the database for a particular exam will belong to one out of the specified number of question categories for that exam. The examiner will specify the number of questions to be answered from each question category. The sum of the number of questions from each category will be the total number of questions each candidate will attempt/answer. Questions of the same category will have equal strength and candidates will answer equal number of questions from each and every category. This brings in fairness to all candidates by testing or examining each of them on the same equal number of questions and most importantly questions with equal strength. In other words, this eliminate the chances of some candidates getting to answer some questions that are harder or simpler than what some other candidates get even though they are all to be evaluated on the same scale.

The pseudocode to implement Categorization of Questions is:

Step 1: Set the category name and the number of categories and store it in the database

Step 2: For the number of categories specified above, enter the category identifier, the category score (that will be used for each question) and the number of questions to be answered from the category.

Step 3: For each of the question set, pick any of the categoryDetail set in Step 2

2) State Persistency: This is a concept that enables the session (i.e the state) of every user of the proposed system to be saved at a particular interval, thus enabling the ability to resume the saved state after restoration from any interruption that might have occured during the course of conducting the examination. The state persistency have several advantages, but one of the most important of this is the application of it to handle the issue of power interruption which always cause the examination process to be restarted.

The Pseudocode to implement State Persistency is:

Step 1: Check for validity of the login credential presented by student, If valid Proceed to Step 2 else END.

Step 2: Check whether the student is logging-in for the first time for the examination under consideration. If yes, step 4 otherwise step 3

Step 3: Load and Unserialize the student's data from the file, Load questions from the file and proceed to step 5.

Step 4: Create a file and name it with the student's ID, Load fresh questions for the student, serialize the students object and save it in the file.

Step 5: Start Exam and as the students navigate through the question, serialize the current states and save to the file.

Step 6: If the exam is submitted successfully, then delete the file and END else go to step 1.

3) Addition of Response Type Question : This is the type of question that requires students to supply textual answer by typing from the keyboard rather than selecting from available options (say a, b, c, d or e). This type of question requires strict and consistent response from candidates as it does not allows for guessing unlike the multiple choice questions.

Below is the Archtecture of the proposed system. 


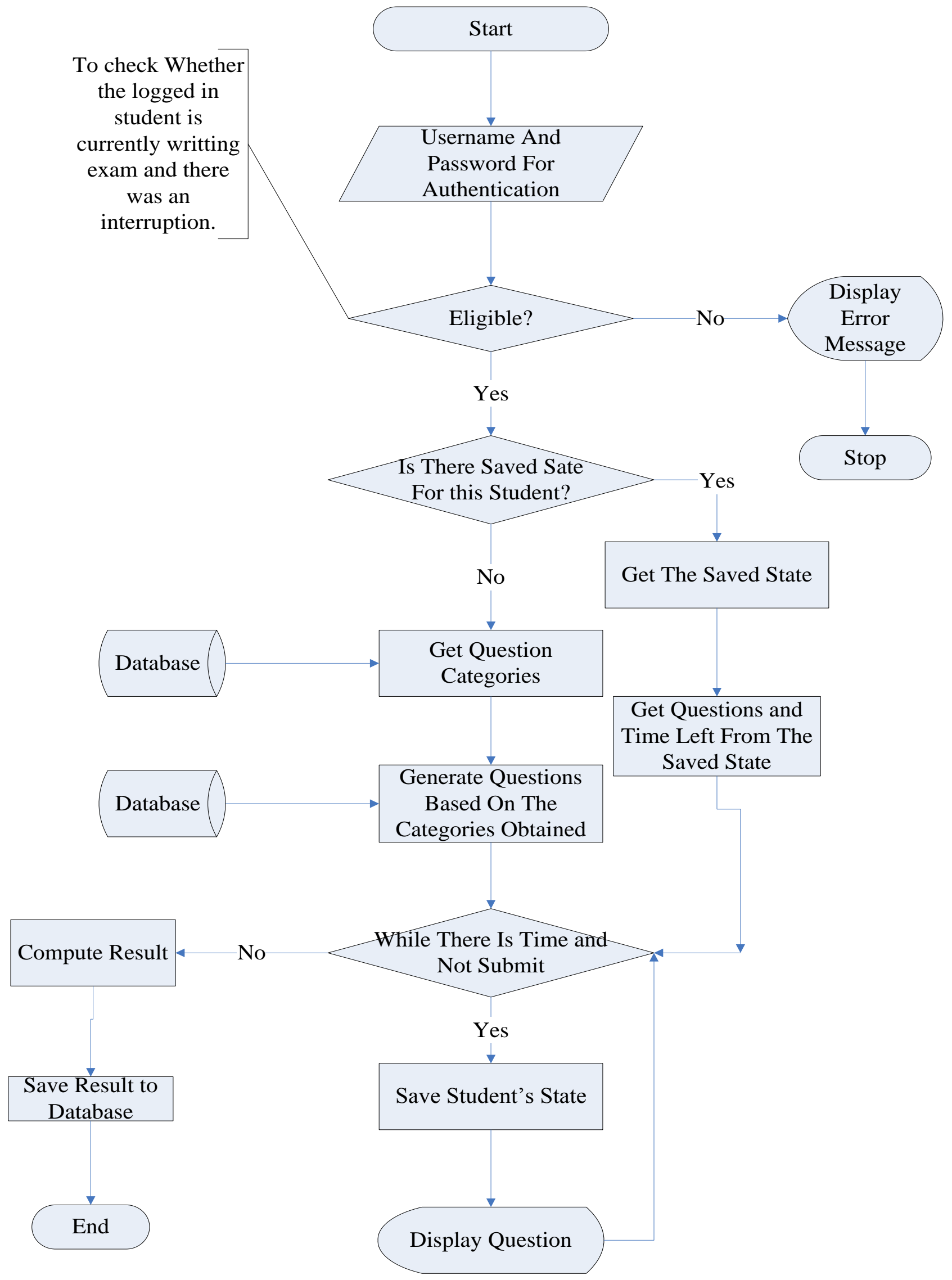

Fig 2: Architecture of the Proposed system. 


\section{IMPLEMENTATION}

Due to the dynamic nature of programming, there are several ways that can be used to implement the concepts discussed above.

The implementation of the Question Categorization feature was done by separating the process of setting questions on the CBT system into a separate module and implemented the module as separate software we called Question Setter. The following are the functions that can be carried out on the Question Setter software:

- Setting Up of the Examination (i.e. the exam details).

- Setting the Question's Categories for the examination.

- Setting Questions for the examination and .

- Generation of questions file for the Computer Based Test System.

The State Persistency feature was implemented using Serialization and Deserialization:

Serialization is the process of creating data format that can be stored into any medium of storage or transmitted across a network connection from an object or a data structure. Each programming language has its own way of implementing this concept. It allows an object to be converted into a format that can be re-used over a period of time [4]. A serialized object (i.e. the resultant object of serialization) can be processed to create a semantically identical clone of the original object through the opposite process known as deserialization.

The State persistency was simply implemented by serializing the students object which holds all the student's Questions, the answers, the time left to complete the examination, the current question's number been answered by the student and the student's personal details. This serialized data will be saved in a file with the student ID as the file name. When a student is logged in, the system will identify the student's file (if there is one) and load the student's data from the file. If the loading of the data is successful, then the data in the file will be deserialized to the student's object and the examination will continue from the state which the student was before the interruption occured. But if the loading of the file is not successful, then new questions will be loaded from the database and as the student proceed in answering the questions, the state (i.e. data) will be saved at an interval. If the examination is submitted by the student or the time elapses, result will be computed and saved into the database. The file containing the student's state will be deleted.

All major programming languages provide inbuilt libraries for implementing serialization. We used C\#.NET to implement this concept of serialization [5].

Lastly, the implementation of response type question on the propsed system was done by setting question and specify a specific, non ambiguous and consistent answer for the question, this will be saved in the database. Candidates are also expected to type this answer specifically as it was saved in the database. This will not only increase the type of questions that can be answered on the CBT system but also ensure that the students really understand the question rather than just picking from available options.
Table 2 enlists the question types that will be taking on the proposed system.

Table 2: Question Types

\begin{tabular}{|c|c|c|c|}
\hline $\mathrm{S} / \mathrm{N}$ & $\begin{array}{l}\text { QUESTION } \\
\text { TYPE }\end{array}$ & $\begin{array}{l}\text { HTML FORM } \\
\text { TYPE }\end{array}$ & COMMENTS \\
\hline 1 & $\begin{array}{l}\text { Multiple choice } \\
\text { questions [many } \\
\text { options (4)] }\end{array}$ & Radio Buttons & $\begin{array}{lr}\text { One } & \text { correct } \\
\text { from } & \text { many } \\
\text { options } & \text { [one } \\
\text { answer } & \\
\text { excludes } & \end{array}$ \\
\hline 2 & $\begin{array}{l}\text { True/false } \\
\text { questions[2 } \\
\text { options] }\end{array}$ & Radio Buttons & $\begin{array}{l}\text { True/false [one } \\
\text { answer } \\
\text { excludes others] }\end{array}$ \\
\hline 3 & $\begin{array}{l}\text { Multiple correct } \\
\text { questions }\end{array}$ & Checkboxes & $\begin{array}{l}\text { Questions with } \\
\text { many correct or } \\
\text { wrong options } \\
\text { [one answer } \\
\text { does not } \\
\text { exclude others] }\end{array}$ \\
\hline 4 & $\begin{array}{ll}\text { Supply } & \text { Type } \\
\text { Questions } & \end{array}$ & Textboxes & $\begin{array}{l}\text { Question that } \\
\text { requires answer } \\
\text { to be typed. }\end{array}$ \\
\hline
\end{tabular}

\section{CONCLUSION AND FUTURE WORK}

The main features for improvement identified in the current CBT System and their implementation were discussed. It is pertinent to state that the implementation of these new features on the current system will go a long way in increasing the fairness, credibility, applicability of the CBT system. Real time evaluation of the operational performance of the implemented features and comparative study will be carried out as future work.

\section{REFERENCES}

[1] Yuan, Z. Zhang, L and Zhang, G. (2003) A Novel WebBased Examination System For Computer Science Education. 33rd ASEE/IEEE Frontiers in Education Conference.S3f-7-s3f-10.

[2] Stina, B. Micheal, T. Stephen, G. and Roberto, T. (2000) PILOT: An Interactive Tool for Learning and Grading, SIGCSEB; SIGCSCE Bulletin, 2000.

[3] Ayo, CK Akinyemi, IO Adebiyi, AA \& Ekong, U O 2007, "The prospects of e-examination implementation in Nigeria", Turkish Online Journal of Distance Education, vol. 8, no 4, pp. 125-134.

[4] Wikipedia, http://en.wikipedia.org/wiki/Serialization visited on 23rd of September 2011.

[5] Microsoft developer network, msdn 2008 version. 